
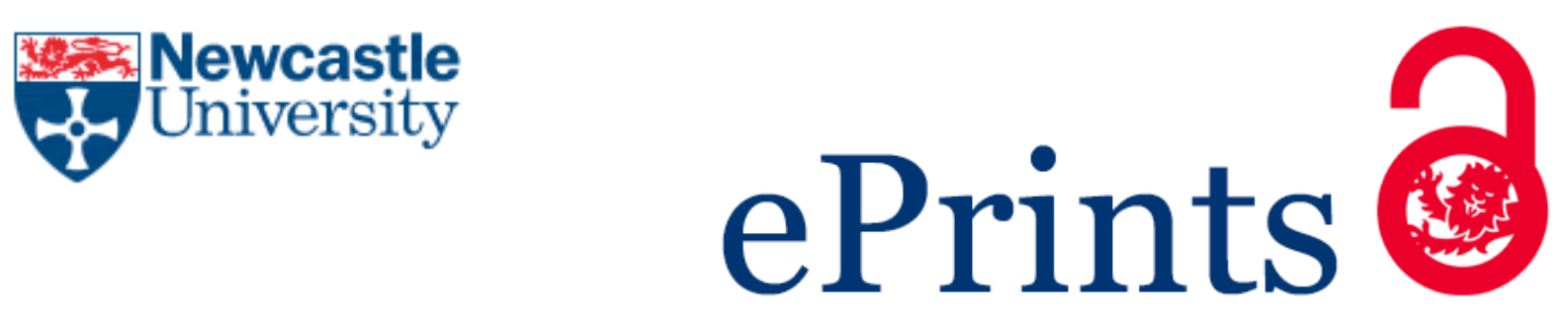

Torelli E, Manzano M, Srivastava SK, Marks RS.

DNA origami nanorobot fiber optic genosensor to TMV.

Biosensors and Bioelectronics 2018, 99, 209-215.

\title{
Copyright:
}

(C) 2018. This manuscript version is made available under the CC-BY-NC-ND 4.0 license

DOI link to article:

https://doi.org/10.1016/i.bios.2017.07.051

Date deposited:

$22 / 08 / 2017$

Embargo release date:

21 July 2018

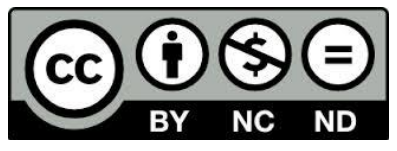

This work is licensed under a

Creative Commons Attribution-NonCommercial-NoDerivatives 4.0 International licence 


\section{DNA origami nanorobot fiber optic genosensor to TMV}

Emanuela Torellia,b, $1^{*}$, Marisa Manzano ${ }^{\mathrm{a}, \mathrm{b}}$, Sachin K. Srivastava ${ }^{\mathrm{a}}$ \& Robert S. Marksa, $\mathrm{a}^{\mathrm{a} \mathrm{c}^{*}}$

aNanyang Technological University-Hebrew University of Jerusalem-Ben Gurion University (NEW-CREATE) Programme, 1 CREATE Way, Research Wing, \#02-06/08, Singapore 138602, Singapore

bDipartimento di Scienze Agroalimentari, Ambientali e Animali

University of Udine, via delle Scienze 206, 33100 Udine, Italy

'Ben-Gurion University of the Negev, Department of Biotechnology Engineering, P.O. Box 653, 84-105 BeerSheva, Israel

${ }^{1}$ Present address: Interdisciplinary Computing and Complex BioSystems (ICOS), School of Computing Science; Centre for Synthetic Biology and Bioeconomy (CSBB); Centre for Bacterial Cell Biology (CBCB). Newcastle University, Newcastle upon Tyne, NE1 7RU, U.K.

${ }^{*}$ Corresponding authors.

E-mail addresses: rsmarks@bgu.ac.il (R.S. Marks); emanuela.torelli@newcastle.ac.uk (E. Torelli).

\section{Abstract}

In the quest of greater sensitivity and specificity of diagnostic systems, one continually searches for alternative DNA hybridization methods, enabling greater versatility and where possible field-enabled detection of target analytes. We present, herein, a hybrid molecular self-assembled scaffolded DNA origami entity, intimately immobilized via capture probes linked to aminopropyltriethoxysilane, onto a glass optical fiber end-face transducer, thus producing a novel biosensor. Immobilized DNA nanorobots with a switchable flap can then be actuated by a specific target DNA present in a sample, by exposing a hemin/G-quadruplex DNAzyme, which then catalyzes the generation of chemiluminescence, once the specific fiber probes are immersed in a luminol-based solution. Integrating organic nanorobots to inorganic fiber optics creates a hybrid system that we demonstrate as a proof-of-principle can be utilized in specific DNA sequence detection. This system has potential applications in a wide range of fields, including point-of-care diagnostics or cellular in vivo biosensing when using ultrathin fiber optic probes for research purposes.

Keywords: optical fiber; 3D DNA origami nanorobot; switchable nanodevice; genosensor

\section{Introduction}

DNA origami technology enables increased control in self-assembly of 2D (Endo et al., 2015; Kozyra et al., 2017; Marini et al., 2011; Piantanida et al., 2015; Rothemund, 2006) and 3D nanoscale complex structures 
(Andersen et al., 2009; Douglas et al., 2009; Douglas et al., 2012; Schüller et al., 2011; Torelli et al., 2014; Zadegan et al., 2012) of purpose designed shaped nanomaterials exhibiting high precision and specificity (Tørring et al., 2011). The method uses hundreds of short oligonucleotide 'staple' strands to direct the folding of a long single 'scaffold' strand of DNA into a pre-programmed arrangement (Rothemund, 2006).

To date, self-assembled DNA nanostructures have demonstrated a great potential in a wide range of innovative applications due to its programmable control of shape and size, precise spatial addressability, easy and high-yield preparation, and biocompatibility (Pandian and Sugiyama, 2016; Wang et al., 2013). Previous applications with DNA origami were found in photonics, therapeutics, nanofabrication and nanomechanics (Angell et al., 2016; Chandrasekaran et al., 2016; Chao et al., 2014; Peng et al., 2016; Kearney et al., 2016; Kuzuya and Ohya, 2014; Yang et al., 2015a; Yonamine et al., 2016). DNA nanostructures have been used previously for sensing applications. Self-assembled nucleic acid probe tiles were created for label-free detection of RNA: a ssDNA overhang can act as hybridization probes for specific RNA targets in solution and the ability to detect single molecule hybridization was explored (Ke et al., 2008). Also Koirala et al. (2014) used 2D and 3D DNA origami nanoassembly for the detection of multiple DNA synthetic targets anticipating a new sensing strategy. In a different approach, a switchable 2D DNA origami was used to detect the presence of synthetic DNA target (Marini et al., 2011).

Many applications are not only dependent on the structural design of the origami, but also on its immobilization to solid phase interphases or surfaces (Pillers et al., 2015). The immobilization of DNA nanostructures on a glass surface is a key step for the integration of DNA nanorobot onto optical fiber tips for sensing applications. Some immobilization on glass methodologies of 3D purpose DNA are known (Gietl et al., 2012), including with nanoantennas (Puchkova et al., 2015), nanopores (Bell et al., 2013; HernándezAinsa et al., 2013) and wafer pattern (Linko et al., 2015). DNA nanostructures can be selectively guided and anchored on glass capillaries by trapping them once a positive voltage is applied to a reservoir (Bell et al., 2013; Hernández-Ainsa et al., 2013). Recently, it has been shown that DNA origami can be uniformly deposited by a spray-coating technique without using pre-treatment of the substrate (Linko et al., 2015). Nevertheless, the aforementioned methods could anchor the nanostructures on the glass interface in a way that would inhibit the actuation mechanism of the immobilized 3D DNA nanorobots, including changing its conformation from a closed state to an open one or making it unresponsive. Herein we utilized a DNA origami immobilization strategy that allows their immobilization to glass optical fibers, thereby enabling the use of a DNA origami, acting as a functional smart molecular device without losing its switchable feature, 
despite its solid-phase immobilization.

The motivation to combine the undisputed potential of DNA origami (i.e. addressability, versatility and loading capabilities) to the unique advantages of optical fiber transducers has been the key factor at the base of our new organic-inorganic hybrid system. We are the first, to the best of our knowledge to conjugate 3D DNA origami to an optical fiber transducer thereby producing a DNA origami genosensor. This new system could find use in many applications, such as diagnostics or water monitoring for pathogens.

\section{Material and methods}

\subsection{Materials and reagents}

Hemin was purchased from Porphyrin Products (Logan, UT) and used without other purification. A hemin stock solution $(5 \mathrm{mM})$ was prepared in DMSO and stored in the dark at $-20^{\circ} \mathrm{C}$. Oligonucleotides without any modification and with Alexa 488 label at the 5' end were purchased from Integrated DNA Technologies Pte Ltd (Singapore) and were resuspended in sterile MilliQ water to give stock solutions of $100 \mu \mathrm{M}$. Capture sequence, anchor sequence and labeled nucleotide sequences are shown in Supplementary Information, Table S1. In the 3D DNA origami used in this work, 6 previously published sequences (Torelli et al., 2014) were labeled with Alexa 488 and one sequence (anchor sequence) was elongated in order to permit the attachment of the complementary capture sequence. 3D DNA nanorobot design was produced in caDNAno software from Douglas et al. (2009). M13mp18 was purchased from Bayou Biolabs, LA, USA. Xmnl enzyme and bovine serum albumin molecular biology grade were purchased from New England Biolabs, Singapore. All other chemicals were purchased from Sigma-Aldrich Pte Ltd (Singapore).

SFS400/440B Superguide G UV-Vis silica fibers (Fiberguide Industries, Stirling, USA) were used for all experiments. The fibers had an original numerical aperture (NA) of 0.22 , a core diameter of $400 \mu \mathrm{m}$ (refractive index of 1.457 at $633 \mathrm{~nm}$ ) and a surrounding silica cladding with a width of $40 \mu \mathrm{m}$ (refractive index of 1.44 at $633 \mathrm{~nm}$ ), in addition to a $150-\mu \mathrm{m}$-thick silicon buffer and a $210-\mu \mathrm{m}$-thick black Tefze ${ }^{\circledR}{ }^{\circledR}$ jacket. The length of a single fiber used in the experiments was $20 \mathrm{~cm}$. The black Tefzel ${ }^{\circledR}$ jacket and silicon buffer were mechanically stripped away using a fiber stripping tool (Micro-Strip ${ }^{\circledR}$, from Micro-Electronics Inc., USA) to expose a $2 \mathrm{~mm}$ naked optical fiber core tip.

\subsection{D DNA origami}

The square-lattice version of the caDNAno software from Douglas et al. (2009) was used and 3D DNA origami was synthesized and purified as previously described (Torelli et al., 2014). Image J was used for gel 
image analysis to estimate the yield of purification (Abramoff et al., 2004).

\subsection{Probe and target design}

Sequences were previously drawn using the program BioEdit v.7.0.9 (Marini et al., 2011; Torelli et al., 2014). The probe was designed to target the TMV nucleocapsid gene whose gene sequence was retrieved from the NCBI database (accession number LN651239.1, KM407602.1, KJ406323.1, GQ370524.1, AJ239099.1). The specificity was confirmed in silico by aligning the probe sequences using BLASTn, available at the NCBI GenBank database.

\section{$2.43 D$ DNA origami gel electrophoresis}

Folded and purified DNA-origami were run on a $0.7 \%(w / v)$ agarose gel (SeaKem Agarose, Lonza): gels were previously added with $0.5 \times$ Gel Red ${ }^{\mathrm{TM}}$ nucleic acid stain (Biotium, Hayward, CA) and run in $1 \times$ TAE (for $200 \mathrm{ml}$ of a 50x buffer solution: $400 \mathrm{mM}$ Tris- $\mathrm{HCl}, 11.42 \mathrm{ml}$ acetic acid, $20 \mathrm{ml}$ EDTA $0.5 \mathrm{M}, \mathrm{pH}$ 8.0) at $75 \mathrm{~V}$ for 45 minutes and then visualized and photographed under UV light (Molecular Imager Gel Doc ${ }^{\mathrm{TM}}$ XR+ Imaging System, Biorad). The $1 \mathrm{~kb}$ DNA ladder (Sigma-Aldrich, Singapore) was used as a molecular weight marker.

\subsection{D DNA origami and Transmission Electron Microscopy (TEM) imaging}

For TEM imaging $10 \mu \mathrm{l}$ of the samples were adsorbed for 3 minutes on carbon-coated copper grids and imaged with a JEOL JEM 1011 transmission electron microscope (Tokyo, Japan) operating at $100 \mathrm{kV}$. The samples were stained for 2 minutes with a $2 \%(\mathrm{w} / \mathrm{v})$ uranyl acetate solution and washed in milliQ water for three times.

\subsection{D DNA origami and Atomic Force Microscopy (AFM) imaging}

Samples were dispersed on the negative mica surface using 10x TAEM buffer and let deposit for 5 minutes. AFM images were obtained as previously described (Torelli et al., 2014).

\subsection{Silanization of glass slides, capture probe binding and DNA origami attachment}

The initial solid phase support used were microscope cover glasses, then silanized (Manzano et al., 2015; Marcello et al., 2013) with some modifications. The cover glasses were treated with $10 \%(\mathrm{w} / \mathrm{v}) \mathrm{NaOH}$ at room temperature for 1 hour, rinsed with deionized water and treated with $0.1 \mathrm{M} \mathrm{HCl}$ for 15 minutes. After a washing step with deionized water, the glass slides were rinsed in acetone and dried at $50^{\circ} \mathrm{C}$ for a few minutes, and immersed in a $0.5 \%(\mathrm{v} / \mathrm{v})$ APTES solution in deionized water for 30 minutes at room temperature. Slides were then rinsed three times in deionized water, dried at $160^{\circ} \mathrm{C}$ for 1 hour and cooled at 
room temperature for 30 minutes. $10 \mu \mathrm{l}$ drops of the capture probe at $100 \mathrm{ng} / \mu \mathrm{l}$ were deposited in triplicate on each glass slide and incubated at $4{ }^{\circ} \mathrm{C}$ overnight to conjugate the microscope cover glass surface.

The glass slides with the bound capture probe were washed twice in deionized water prior to utilization. Then, $1 \mu \mathrm{l}$ or $10 \mu \mathrm{l}$ of the 3D DNA origami samples was spotted on each slide. The microscope cover glasses were incubated at room temperature for $2 \mathrm{~h}$ in the dark and they were washed twice in sterile deionized water to eliminate the unbound DNA nanostructures.

\subsection{Silanization of the optical fiber tips and capture probe binding}

In preparation for the silanisation procedure, fibers were soaked in a 1:1 methanol/37\% $(\mathrm{v} / \mathrm{v}) \mathrm{HCl}$ solution for 10 minutes to purify the newly exposed fiber core from micro-contaminants. After sonication for 10 minutes, the fiber tips were dried under $\mathrm{N}_{2}$ and dipped in Piranha solution $\left(35 \% \mathrm{H}_{2} \mathrm{O}_{2}: 96 \% \mathrm{H}_{2} \mathrm{SO}_{4}\right.$ in the ratio $3: 7$ ) for 15 minutes at $90^{\circ} \mathrm{C}$ to enhance the exposure of the hydroxyl groups on the silica surface. After a washing step with deionized water, the glass tips were rinsed in acetone and dried at $40{ }^{\circ} \mathrm{C}$ for a few minutes, and immersed in a $0.5 \%$ APTES solution in sterile deionized water for 30 minutes at room temperature. In the presence of water, the hydrolysis of ethoxy groups of APTES and their condensation into siloxane (Si-O-Si) occur, leading to the formation of a silane layer. The amino group it self is believed to act as a catalyst and enhance the adsorption rate of APTES molecules on glass surfaces (Metwalli et al., 2006). Fiber tips were then rinsed three times in deionized water and acetone. APTES films were cured in an oven at $80^{\circ} \mathrm{C}$ for 3 hours: heat treatment helps to inter-crosslink the silane molecules on the surface though the elimination of water molecules forming a relatively more robust silane layer. Curing at high temperature in the presence of surface water increased the number of siloxane bonds in APTES film. During heat curing, silanes condensed rapidly to siloxanes (Vandenberg et al., 1991). After incubation at room temperature for 30 minutes, fibers were incubated in $25 \mu \mathrm{l}$ of the capture probe at $100 \mathrm{ng} / \mu \mathrm{l}$ at $4{ }^{\circ} \mathrm{C}$ overnight. The fibers with the bound capture probe were washed twice in deionized water prior to utilization.

\subsection{Field Emission Scanning Electron Microscopy (FE SEM)}

Silanized optical fibers were visualized using Supra 55 Field Emission SEM, Carl Zeiss. Since the surface was non-conducting, the operating gun voltage and detectors (In-Lens or SE) were chosen in a manner to get clear images of the silanized surface.

\subsection{Fluorescence microscopy}

Glass slides and optical fibers with fluorescently labelled 3D DNA origami were imaged using a Leica 
fluorescent microscope AF6000 equipped with a 10x and 20x magnification objectives. The external light source was a Leica EL6000 lamp (HXP 120 W 45C VIS-Osram, Metal Halogenide bulb). The Alexa 488 labeled DNA nanostructures were excited at $501 \mathrm{~nm}$ and the fluorescence emission at $521 \mathrm{~nm}$ in wavelength was collected. The fluorescence emission intensity was calculated using Image J (Schneider et al., 2012).

\section{$2.113 D$ DNA origami attachment to fiber tips and actuation mechanism}

In order to ensure the 3D DNA origami attachment to the glass surface through the protruding anchor probe sequence complementary to the capture probe, fibers were immersed in a solution of 3D DNA origami and incubated for 2 hours and 30 minutes at $25^{\circ} \mathrm{C}$. After washing steps, fibers with immobilized 3D DNA origami were placed in a $0.5 \mathrm{ml}$ conical tube containing $8 \mathrm{ng} / \mu \mathrm{l}$ or $4 \mathrm{ng} / \mu \mathrm{l}$ of nucleic acid target in $1 \mathrm{x}$ TAEM hybridization buffer (10x TAEM solution:125 mM MgCl $2,400 \mathrm{mM}$ Tris- $\mathrm{HCl}, 10 \mathrm{mM}$ EDTA pH 8.0) or in the same solution without target, and allowed to react for 1 hour. Then, hemin $(1.6 \mu \mathrm{M})$ was added to the same solution and fibers were incubated for 30 minutes at $25^{\circ} \mathrm{C}$ to allow the hemin/G-quadruplex stuctures conjugation. A hemin/DNAzyme standard solution was used with the fiber without immobilized DNA origami as positive control.

\subsection{Chemiluminescent assay}

Chemiluminescence measurements were conducted using a Hamamatsu HC135-01 Photo Multiplier Tube (PMT) Sensor Module, combining the sensitivity of a photomultiplier tube with the intelligence of a microcontroller. The instrument was placed in a light-tight box and to prevent damage to the photon-counting unit by environmental light a manual shutter (71430, Oriel) was placed in front of the detector. To move the slide shutter of the photon counting unit, a custom-made lever was placed outside the box. After the incubation in the hybridization buffer, the optical fibers were removed from the $0.5 \mathrm{ml}$ conical tubes and the fibers tips were washed twice in sterile deionized water: the far end of each fiber was held by a fiber holder (FPH-DJ, Newport) and placed into an adjustable single-fiber mount (77837, Oriel), as previously reported (Eltzov et al., 2009; Polyak et al., 2001). Then the optical fibers tips were dipped in a solution containing 6.6 $\mu \mathrm{l}$ of $5 \mathrm{mM}$ luminol and $20 \mu \mathrm{l}$ of $\mathrm{H}_{2} \mathrm{O}_{2}$ solution $(98 \mathrm{mM})$ : the light-tight box was closed and the slide shutter was moved using the outside custom-made lever. DNA origami opening was measured immediately analyzing the light emission intensity as the mean value of the photon counts for a period of 15 seconds: each measurement is presented as the mean of 3 fibers set and reported in arbitrary units (a.u.).

\section{Results and discussion}




\subsection{Device fabrication}

Fiber optics are a convenient material for optical sensor design, because they are inexpensive, flexible and provide miniaturized sensor probe surfaces while being easy to handle and enabling efficient signal delivery and measurement. Several fiber-based technologies have been developed in the past that take advantage of optical fiber's cost effectiveness and its waveguiding capabilities (Cecchini et al., 2012; Fan et al., 2008; Petrosova et al., 2007; Ricciardi et al., 2015; Salama et al., 2007; Sobarzo et al., 2007; Stevens et al., 2016; Torelli et al., 2017; Yang et al., 2015b).

Here, we consider a device consisting of DNA nanorobots immobilized at the endface interfacial surface of the optical fiber core itself acting as the transducing element of the genosensor (Fig. 1). After optical fiber silanization and capture probe binding, 3D DNA origami has been immobilized through hybridization between the protruding anchor probe and the capture probe (Fig. 1, B 1). The immobilized 3D DNA origami is able to respond to an external molecular target stimulus and actuates by a physical switch from a disarmed to an armed configuration. In the presence of a small amount of TMV target DNA, the robot moves a flap promoting the exposition of its cargo DNA and the self-assembly of a stable hemin/G-quadruplex horseradish peroxidase (HRP)-mimicking a DNAzyme (Torelli et al., 2014). The DNA origami-optical fiber sensor was first immersed in a solution containing TMV target sequences enabling molecular recognition and hybridization

(Fig. 1, B 2) and then the test probe was dipped into a luminol-based solution for evaluation of the presence of the target in the test sample (Fig. 1, B 3). The well-folded DNAzyme catalyzes the $\mathrm{H}_{2} \mathrm{O}_{2}$-mediated oxidation of luminol to yield chemiluminescence. The light emitted is collected by the optical fiber and then a measurement is made by a PMT module and analyzed by a computer.

\subsection{DNA nanorobot origami}

DNA nanorobots were prepared by folding the Xmnl digested M13mp18 scaffold strand with staple strands, as previously reported. In our previous work (Torelli et al., 2014), the 3D DNA origami nanorobot was designed, produced, characterized and tested in solution: TEM and AFM images confirmed the correct formation of the 3D DNA origami and the average value of the nano-object was calculated on 1500 nanostructures: their length were estimated at $55 \pm 9$ via AFM and $40 \pm 7 \mathrm{~nm}$ with TEM, smaller than predicted and possibly due to negative staining and air drying (Torelli et al., 2014).

In order to immobilize DNA nanostructures onto the glass surface and verify their attachment using fluorescence microscopy, we used a protruding anchor sequence complementary to a capture sequence and 
Alexa 488 labeled staple strands from six sites of the origami structure. Detail on CaDNAno project are showed in Supplementary Information (Fig. S1). The selective hybridization of anchor and capture sequences was previously demonstrated using fluorescein-labeled oligonucleotides (Strable et al., 2004). 3D DNA origami was successfully self-assembled as shown by agarose gel electrophoresis, TEM and AFM images (Fig. 2, Fig. 3 and Fig. S2). The synthesis resulted in a stable well-folded construct, that migrated during electrophoresis as a distinct band well separated from non-integrated staple strands: the yield of the synthesis and purification process was estimated to be $20 \%$, percentage in accordance to our published data. TEM and AFM imaging showed well-folded DNA origami, similar to our previously reported observations (Torelli et al., 2014).

\subsection{DNA nanorobot immobilization on cover glass slips and optical fiber tips}

Optical fibers require that the active biological recognition molecules be immobilized at their surface usually using the procedure of silanization, which is known to offer a robust and internally cross-linked layer of reproducible thickness (Metwalli et al., 2006), with said monolayers modified with oligonucleotides shown to be stable (Belosludtsev et al., 2001; Chiu et al., 2003), oftentimes, using 3- aminopropyltriethoxysilane (APTES) immobilization on various glass substrates (Manzano et al., 2015; Marcello et al., 2013; Taglietti et al., 2014). In detail Belosludtsev et al. (2001) obtained the electrostatic adsorption of oligonucleotides in water to an amino-derivatized glass surface: after the glass silanization with APTES and the stable silane monolayer formation, capture probes were "trapped" upon the surface and were free to form a double helix with complementary DNA. More recently, the same strategy has been reported to produce sensitive biochip for protein or DNA fluorescence detection (Manzano et al., 2015; Marcello et al., 2013). Taking this into account, we, at first, linked short oligonucleotide capture sequences to a glass support by electrostatic adsorption onto positively charged glass surfaces obtained after silanization. The immobilization method consists of five main steps: Piranha solution treatment to introduce hydroxyl group, silane grafting of the glass surface of the optical fiber tips using an aqueous solution of APTES, curing at high temperature to increase siloxane bonds (Metwalli et al., 2006; Vandenberg et al., 1991; Vashist et al., 2014), deposition of capture polynucleotide sequences dispersed in a water solution for immobilization onto the cationic aminosilanized surface, and finally, hybridization between the adsorbed capture sequence and the DNA nanorobot protruding anchor sequence as developed earlier (Fig. S3).

Silanized optical fibers were characterized by Field Emission SEM (Fig. 4). The silane layer over the optical fiber surface, as compared to that of a bare fiber was observed. Deposition of APTES from water resulted in 
a uniform monolayer with occasional aggregates, as previously reported (Metwalli et al., 2006; Vandenberg et al., 1991). In the presence of aggregates, the visualization of DNA nanostructures on silanized glass using AFM is difficult: for this reason fluorescence microscopy was instead used in order to demonstrate the feasibilty of our method.

Indeed, others have exploited a spray-coating technique in order to deposit different 2D and 3D DNA origami nanostructures and the results were then verified using either AFM or fluorescence microscopy depending on the shape of the DNA origami (Linko et al., 2015). If 3D DNA origami was deposited, optical microscopy was used instead of AFM in order to demonstrate the deposition; indeed, structural details of 3D DNA origami on glass surface were hardly visible. Thus, we also used fluorescence microscopy to demonstrate DNA origami nanostructures immobilization on glass surface considering also that the presence of APTES islands clearly interfered with AFM imaging of thin nanostructures which required a smooth surface to enable optimal imaging.

The amino-silanization of a glass surface, creates a negatively charged surface, which enables the stable capture of the negatively charged phosphate backbone of the capture-anchor DNA oligonucleotide sequence Belosludtsev et al., 2001), thus, enabling, after several washing steps and incubation with Alexa 488-labeled DNA origami nanorobots to attach the latter. This was verified by optical fluorescence microscopy. Green fluorescence microscopy images (at $501 \mathrm{~nm}$ excitation) of both cover glasses and optical fibers with and without DNA origami confirmed high fluorescence intensity (the cover glass fluorescence emission intensity was 2735330 a.u. and the optical fibers fluorescence emission intensity was 1133228 a.u.) with only functionalized labeled DNA nanorobot surfaces, also implying successful APTES silanization (Luo et al., 2014; Wang et al., 2009). 3D DNA origami nanostructures were successfully immobilized on silanized glass optical fibers (Fig. S4, A). On the other hand, when optical fibers were not silanized, the nanostructures were removed from glass surface during the washing steps required after the incubation of the optical fibers in the solution of 3D DNA origami (Fig. S4, B).

Even though, fluorescence microscopy demonstrated that the spray large-scale deposition of 3D DNA origami on glass (Linko et al., 2015), does not require washing steps it may, however, affect the opening mechanism of dynamic DNA origami. Here we pioneered a simple approach to immobilize 3D DNA origami on glass surfaces which permits the unrestricted actuation mechanism of 3D nanostructures, requiring fewer steps and being less expensive compared to other methods based on biotin-streptavidin linkage (Gietl et al., 2012; Puchkova et al., 2015). 


\subsection{DNA nanorobot-optical fiber genosensor}

To test the switchable nature of DNA origami, Marini et al. (2011) characterized a $100 \mathrm{~nm}$ 2D circular DNA origami nanoactuator with a prototype flap by combining Förster resonance energy transfer (FRET), AFM and TEM. The flap movement process has been monitored by microscopy: both AFM and TEM images clearly showed a hole within the circular DNA origami due to the flap movement. Moreover fluorescent signal intensity increased after the target addition when 6'-FAM fluorophore and a BHQ-1 quencher has been used as FRET couple. Subsequently, the flap developed on the 2D DNA origami (Marini et al., 2011) has been reduced in size and included in the smaller cylindrical 3D DNA origami nanorobot. The flap opening (due to the same TMV target sequence and probe sequence) has been demonstrated using FRET, colorimetric assay based on the oxidation of $\mathrm{ABTS}^{2-}$ by $\mathrm{H}_{2} \mathrm{O}_{2}$ and chemiluminescent assay in the presence of luminol/ $/ \mathrm{H}_{2} \mathrm{O}_{2}$ (Torelli et al., 2014). Herein, we conjugated the switchable 3D DNA nanorobot to optical fiber tips to detect target DNA via chemiluminescence generation due to the nanoactuation mechanism previously carefully characterized.

As shown in Fig. 5 , the activation of the flap movement with a minimum amount of $4 \mathrm{ng} / \mathrm{\mu l}$ of target DNA was detected using a PMT module. Once an origami nanorobot has been conjugated to the surface of fiber optic endface, one can expose it to a target analyte. Our particular origami nanorobot has been engineered to bind to target TMV ssDNA. Thereafter the flap exposed in the exterior an horseradish molecule whose presence was detected using a substrate, luminol. The oxidized luminol produced light as a side-reaction, which was quantified and thus provided us with the estimated number of target analytes sought. The graphs (Fig. 5) clearly shows a two-fold signal increase with a doubling of the concentration of the analyte. As the chemiluminescence system DNAzyme-luminol- $\mathrm{H}_{2} \mathrm{O}_{2}$ promotes a fast reaction, an high light production was observed at the beginning (in red, Fig. S5), immediately after the slide shutter movement. Then the light emission intensity decreased until reaching a stable low level comparable to the background and to the negative control (non-actuated DNA origami; in grey, Fig. S5). The light emission values of the non-actuated DNA origami (in grey, Fig. S5) were comparable to the background values (in black, Fig. S5): indeed the DNAzyme can be available for the interaction with hemin only after the activation of the flap movement due to the target addition.

The limit of detection corresponding to a light emission intensity value of 104 arbitrary units was calculated based on the standard deviations of the blank (10 independent measurements). Significant variations in chemiluminescence intensities were obtained with ssDNA complementary to the probe. Thus, origami-based 
probes, designed to be complementary to the nucleocapsid gene of TMV, hybridized specifically with the target. No variation in chemiluminescence was recorded when a non target nucleic acid was added to the origami solution. The specificity, evidenced by the clear discrimination between signals produced by the detection of the target and non-target, were promising for the future implementation of our hybrid system.

The above results were in agreement with our previous data. To confirm the movement of the flap in an open position, an assay based on the generation of chemiluminescence in the presence of luminol/ $/ \mathrm{H}_{2} \mathrm{O}_{2}$ was reported. In our previous work, all the experiments were conducted using micro-cuvettes containing $\mathrm{H}_{2} \mathrm{O}_{2}$ and actuated DNA origami: the luminol solution was injected into a micro-cuvette and the DNA origami opening was measured immediately with a CCD detector analyzing the light emission intensity (Torelli et al., 2014). Here we go a step further introducing a portable genosensor. In summary, at first we coupled DNA origami intimately to the surface of a glass optical fiber. The detection scheme combines the intrinsic recognition abilities of the immobilized switchable DNA nanorobots with a chemiluminescence signal collection coupled to a portable transducer. Therefore, we constructed a fully functional and self-contained sensing device for viral detection of TMV without the need for a lab as it may be dispatched with our proprietary portable photodetector.

\section{Conclusions}

Due to the self-recognition properties of DNA molecules, it is possible to create numerous artificial DNA nanostructures with well-defined structures and DNA nanodevices with precisely controlled motions (Taglietti et al., 2014). Recently a DNA nanorobot triggered by a target DNA strand was designed, produced, characterized and tested (Torelli et al., 2014). Herein, a genosensor was developed based on an APTESssDNA capture probe, which functionalized optical fiber tips, and were conjugated with a dynamic 3D DNA origami bioreceptor for the specific DNA sequence detection of picomoles target analyte in 90 minutes. Fluorescence imaging demonstrated their immobilization at the tip of an optical fiber, and switchable DNA origami can be successfully deposited on glass without loss of their functionality. This novel DNA nanorobotoptical fiber biosensor system, combines the useful solid phase transducer optical fiber with the vast detection possibilities of DNA origami nanotechnology. Based on our proof-of-principle, the proposed hybrid system can be a candidate for different applications. The opening mechanism exposed a DNAzyme useful for the biosensing process, but the cargo can easily be adapted to permit the controlled delivery of therapeutic nucleic acid, e.g. small interfering RNA, aptamers and rybozyme, when ultrathin fiber optic probes are used. The above mentioned nucleic acids can be available only after the activation of the flap 
opening due to the recognition event probe-target. Future directions of this research may also comprise point-of-care diagnostics and cellular in vivo biosensing.

\section{Safety considerations}

Piranha solution is highly toxic, corrosive and reactive and can become extremely hot when prepared; it is corrosive and irritating to the eyes, skin, and respiratory tract. When working with Piranha, it is highly recommended to use only glass containers. During Piranha solutions preparation, it is compulsory to add peroxide solution to acid very slowly in a ventilated fume hood wearing gloves, a lab coat, and goggles.

\section{Acknowledgements}

This Research was supported by NTU-HUJ-BGU Nanomaterials for Energy and Water Management Programme under the Campus for Research Excellence and Technological Enterprise (CREATE), that is supported by the National Research Foundation, Prime Minister's Office, Singapore.

E.T. thanks the EPSRC for funding projects EP/J004111/2 \& EP/N031962/1.

\section{References}

Abramoff, M.D., Magalhaes, P.J., Ram, S.J., 2004. Biophotonics International 11, 36-41.

Andersen, E.S., Dong, M., Nielsen, M.M., Jahn, K., Subramani, R., Mamdouh, W., Golas, M.M., Sander, B., Stark, H., Oliveira, C.L.P., Pedersen, J.S., Birkedal, V., Besenbacher, F., Gothelf, K.V., Kjems, J., 2009. Nature 459, 73-76.

Angell, C., Xie, S., Zhang, L., Chen, Y., 2016. Small 12, 1117-1132.

Bell, N.A.W., Thacker, V.V., Hernandez-Ainsa, S., Fuentes-Perez, M.E., Moreno-Herrero, F., Liedl, T., Keyser, U.F., 2013. Lab on a Chip 13, 1859-1862.

Belosludtsev, Y., Iverson, B., Lemeshko, S., Eggers, R., Wiese, R., Lee, S., Powdrill, T., Hogan, M., 2001. Anal. Biochem. 292, 250-256.

Cecchini, F., Manzano, M., Mandabi, Y., Perelman, E., Marks, R.S., 2013. J. Biotechnol. 157, 25-30.

Chandrasekaran, A.R., Wady, H., Subramanian, H.K.K., 2016. Small 12, 2689-2700.

Chao, J., Liu, H., Su, S., Wang, L., Huang, W., Fan, C., 2014. Small 10, 4626-4635.

Chiu, S.K., Hsu M., Ku W.C., Tu C.Y., Tseng Y.T., Lau W.K., Yan R.Y., Ma J.T., Tzeng C.M., 2003. Biochem. J. 374, 625-632.

Douglas, S.M., Dietz, H., Liedl, T., Hogberg, B., Graf, F., Shih, W.M., 2009. Nature 459, 414-418.

Douglas, S.M., Bachelet, I., Church, G.M., 2012. Science 335, 831-834. 
Eltzov. E., Marks, R.S., Voost, S., Wullings, B.A., Heringa M.B., 2009. Sens. Actuators B 142, 11-18.

Endo, M., Sugita, T., Rajendran, A., Katsuda, Y., Emura, T., Hidaka, K., Sugiyama, H., 2011. Chem. Comm. 47, 3213-3215.

Fan, X., White, I.M., Shopova, S.I., Zhu, H., Suter, J.D., Sun, Y., 2008. Anal. Chim. Acta 620, 8-26.

Gietl, A., Holzmeister, P., Grohmann, D., Tinnefeld, P., 2012. Nucleic Acids Res. 40, doi: 10.1093/nar/gks326. Hernández-Ainsa, S., Bell, N.A.W., Thacker, V.V., Göpfrich, K., Misiunas, K., Fuentes-Perez, M.E., MorenoHerrero, F., Keyser, U.F., 2013. ACS Nano 7, 6024-6030.

Ke, Y., Lindsay, S., Chang, Y., Liu, Y., Yan, H., 2008. Science, 319, 180-183.

Kearney, C.J., Lucas, C.R., O'Brien, F.J., Castro, C.E., 2016. Adv. Mater. 28, 5509-5524.

Koirala, D., Shrestha P., Emura T., Hidaka K., Mandal S., Endo M., Sugiyama H., Mao H., 2014. Angew. Chem. Int. Ed. 53, 8137-8141.

Kozyra, J., Ceccarelli, A., Torelli, E., Lopiccolo, A., Gu, J.Y., Fellerman, H., Stimming, U., Krasnogor, N., 2017. ACS Synth. Biol. http://dx.doi.org/10.1021/acssynbio.6b00271

Kuzuya, A., Ohya, Y., 2014. Acc. Chem. Res. 47, 1742-1749.

Linko, V., Shen, B., Tapio, K., Toppari, J.J., Kostiainen, M.A., Tuukkanen, S., 2015. Sci. Rep. 5, doi:10.1038/srep15634.

Luo, B., Yan, Z., Sun, Z., Li, J., Zhang, L., 2014. Opt. Express 22, 30571-30578.

Manzano, M., Cecchini, F., Fontanot, M., Iacumin, L., Comi, G., Melpignano, P., 2015. Biosens. Bioelectr. 66, 271-276.

Marcello, A., Sblattero, D., Cioarec, C., Maiuri, P., Melpignano, P., 2013. Biosens. Bioelectr. 46, 44-47.

Marini, M., Piantanida, L., Musetti, R., Bek, A., Dong, M., Besenbacher, F., Lazzarino, M., Firrao, G., 2011. Nano Lett. 11, 5449-5454.

Metwalli, E., Haines, D., Becker, O., Conzone, S., Pantano, C.G., 2006. J. Colloid Interface Sci. 298, 825831.

Pandian, G.N., Sugiyama, H., 2016. Bull. Chem. Soc. Jpn. 89, 843-868.

Peng, Z., Liu, H., 2016. Chem. Mater. 28, 1012-1021.

Petrosova, A., Konry, T., Cosnier, S., Trakht, I., Lutwama, J., Rwaguma, E., Chepurnov, A., Mühlberger, E., Lobel, L., Marks, R.S., 2007. Sens. Actuators B 122, 578-586.

Piantanida, L., Naumenko, D., Torelli, E., Marini, M., Bauer, D.M., Fruk, L., Firrao, G., Lazzarino, M., 2015. Chem. Comm. 51, 4789-4792. 
Pillers, M.A., Shute, R., Farchone, A., Linder, K.P., Doerfler, R., Gavin, C.,Goss, V., Lieberman, M., 2015. J. Vis. Exp. 101, doi: 10.3791/52972.

Polyak, B., Bassis, E., Novodvorets, A., Belkin, S. Marks, R.S. 2001. Sens. Actuators B 74, 18-26.

Puchkova, A., Vietz, C., Pibiri, E., Wünsch, B., Sanz Paz, M., Acuna, G.P., Tinnefeld, P., 2015. Nano Lett. 15, 8354-8359.

Ricciardi, A., Crescitelli, A., Vaiano, P., Quero, G., Consales, M., Pisco, M., Esposito, E., Cusano, A., 2015. Analyst 140, 8068-8079.

Rothemund, P.W.K., 2006. Nature 440, 297-302.

Salama, O., Herrmann S., Tziknovsky A., Piura B., Meirovich M., Trakht I., Reed B., Lobel L.I., Marks R.S., 2007. Biosens. Bioelectr. 22, 1508-1516.

Schneider, C.A., Rasband, W.S., Eliceiri, K.W., 2012. Nat. Methods 9, 671-675.

Schüller, V.J., Heidegger, S., Sandholzer, N., Nickels, P.C., Suhartha, N.A., Endres, S., Bourquin, C., Liedl, T., 2011. ACS Nano 5, 9696-9702.

Sobarzo, A., Paweska, J.T., Herrmann, S., Amir, T., Marks, R.S., 2007. J. Virol. Methods 146, 327-334.

Stevens, O., Petterson, I.E.I., Day, J.C.C., Stone, N., 2016. Chem. Soc. Rev. 45, 1919-1934.

Strable, E., Johnson, J.E., Finn, M.G., 2004. Nano Lett. 4, 1385-1389.

Taglietti, A., Arciola, C.R., D'Agostino, A., Dacarro, G., Montanaro, L., Campoccia. D., Cucca, L., Vercellino, M., Poggi, A., Pallavicini, P., Visai, L, 2014. Biomaterials 35, 1779-1788.

Torelli, E., Marini, M., Palmano, S., Piantanida, L., Polano, C., Scarpellini, A., Lazzarino, M., Firrao, G., 2014. Small 10, 2918-2926.

Torelli E., Manzano, M., Marks, R.S., 2017. Sens. Actuators B 247, 868-874.

Tørring, T., Voigt, N.V., Nangreave, J., Yan, H., Gothelf, K.V., 2011. Chem. Soc. Rev. 40, 5636-5646.

Vandenberg, E.T., Bertilsson, L., Liedberg, B., Uvdal, K., Erlandsson, R., Elwing, H., Lundstrom, I., 1991. J Colloid Interface Sci. 147, 103-118.

Vashist, S.K., Lam., E., Hrapovic, S., Male, K.B., 2014. Chem. Reviews 114, 11083-11130.

Zadegan, R.M., Jepsen, M.D.E., Thomsen, K.E., Okholm, A.H., Schaffert, D.H., Andersen, S.E., Birkedal, V., Kjems, J., 2012. ACS Nano 6, 10050-10053.

Wang, Y., Pang, X., Zhang, Y., Wang, H., 2009. Surf. Interface Anal. 41, 775-778.

Wang, Z.G., Song, C., Ding, B., 2013. Small 9, 2210-2222.

Yang, Y.R., Liu,Y., Yan H., 2015a. Bioconjugate Chem. 26, 1381-1395. 
Yang, Q., Wang, H., Chen, S., Lan, X., Xiao, H., Shi, H., Ma, Y., 2015b. Anal. Chem. 87, 7171-7179.

Yonamine, Y., Cervantes-Salguero, K., Minami, K., Kawamata, I., Nakanishi, W., Hill, J.P., Murata, S., Ariga, K., 2016. Phys. Chem. Chem. Phys. 18, 12576-12581.

\section{Figure Captions}

Fig. 1. Schematic of DNA origami-optical fiber genosensor. The reactive part of the fiber optic is the core. This $2 \mathrm{~mm}$ part is exposed by mechanically strip away the external protective jacket $(A)$. The biorecognition elements (3D DNA nanorobot) are immobilized on the surface of the core using a capture sequence (green) and an anchor sequence (purple) (B). The closed 3D DNA origami with the unreacted probe (light blue) is shown in $B, 1$. When the hybridization between 3D DNA origami probe and the target $($ red) occurs $(B, 2)$, the flap opens and the DNA nanorobot exposes an hemin/G-quadruplex DNAzyme (orange) $(B, 3)$. The incorporation of hemin (black dots in B,3) defines a cofactor-utilizing nucleic acid that catalyzes oxidative reaction in the presence of luminol/ $\mathrm{H}_{2} \mathrm{O}_{2}$ (Torelli et al., 2014). The resulting chemiluminescent signals arrive at a photomultiplier tube (PMT) and after passing through the detector/sensor module, they are sent to a computer. 3D DNA origami drawing $(\mathrm{B})$ is reproduced with permission. Copyright Wiley-VCH Verlag GmbH \& Co. KgaA (Torelli et al., 2014).

Fig. 2. Agarose gel electrophoresis of well-folded nanorobot. The assembly reactions of the DNA origami were run on a standard agarose gel GelRed ${ }^{\mathrm{TM}}$ stained and imaged under UV light. Lane from left to right: 1) $1 \mathrm{~Kb}$ DNA ladder; 2) M13mp18 single stranded; 3) Xmnl digested M13mp18 DNA, used as negative control: the lower band is the $2289 \mathrm{nts}$ fragment used as scaffold and incorporated into the three dimensional DNA origami; the upper band is the remaining M13mp18 single stranded; 4) well-folded DNA nanorobot. The arrow shows the folded structure.

Fig. 3. TEM images of the well folded 3D DNA origami nanorobot adsorbed on carbon-coated copper grids and stained with a $2 \%(\mathrm{w} / \mathrm{v})$ uranyl acetate solution. The uranyl ions bind to nucleic acid phosphate groups generating an high contrast essential for imaging DNA nanostructures (white arrows). Scale bar: $20 \mathrm{~nm}$.

Fig. 4. Field Emission SEM micrograph of silanized (A, B) and bare (C, D) optical fiber tip (lateral side view). After purification from micro-contaminants and Piranha treatment, the optical fibers tips are treated with a 0.5 $\%$ APTES solution. Deposition of APTES from water results in a silane layer with occasional aggregates (black arrows underline some aggregates, A) as previously reported (Metwalli et al., 2006; Vandenberg et al., 1991). The bare fiber is not treated with APTES solution and its surface appears completely smooth (C, D).

Fig. 5. Light emission intensity (expressed in arbitray units, a.u.). From left to right: a) background, b) 
hemin/G-quadruplex DNAzyme standard solution, c) hemin/G-quadruplex DNAzyme complex in the absence of the target sequence (closed DNA nanorobot), d) hemin/G-quadruplex DNAzyme complex in the presence of the target sequence at a final concentration of $4 \mathrm{ng} / \mu \mathrm{l}$ and e) at a final concentration of $8 \mathrm{ng} / \mu \mathrm{l}$ (actuated DNA nanorobot). (mean \pm standard deviation, $\mathrm{n}=3$ ).

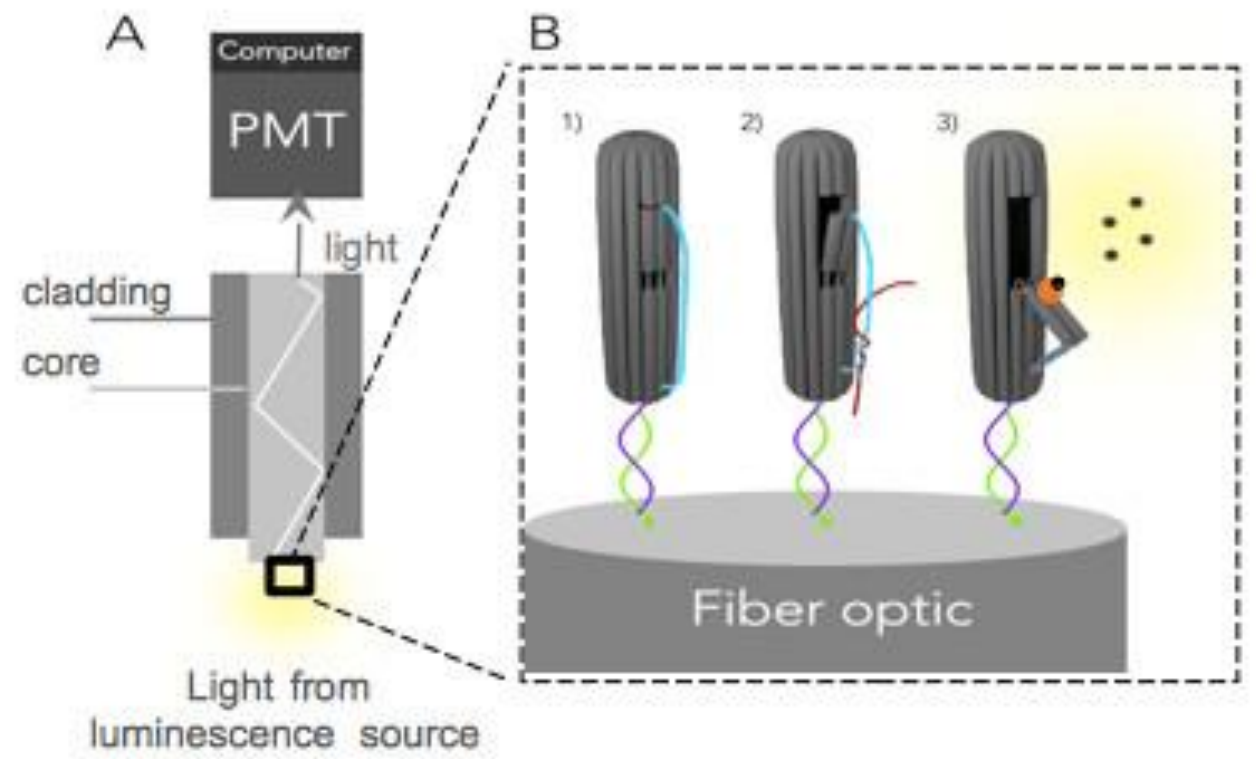

Figure 1.

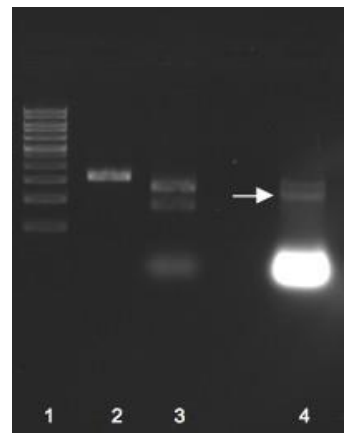

Figure 2. 

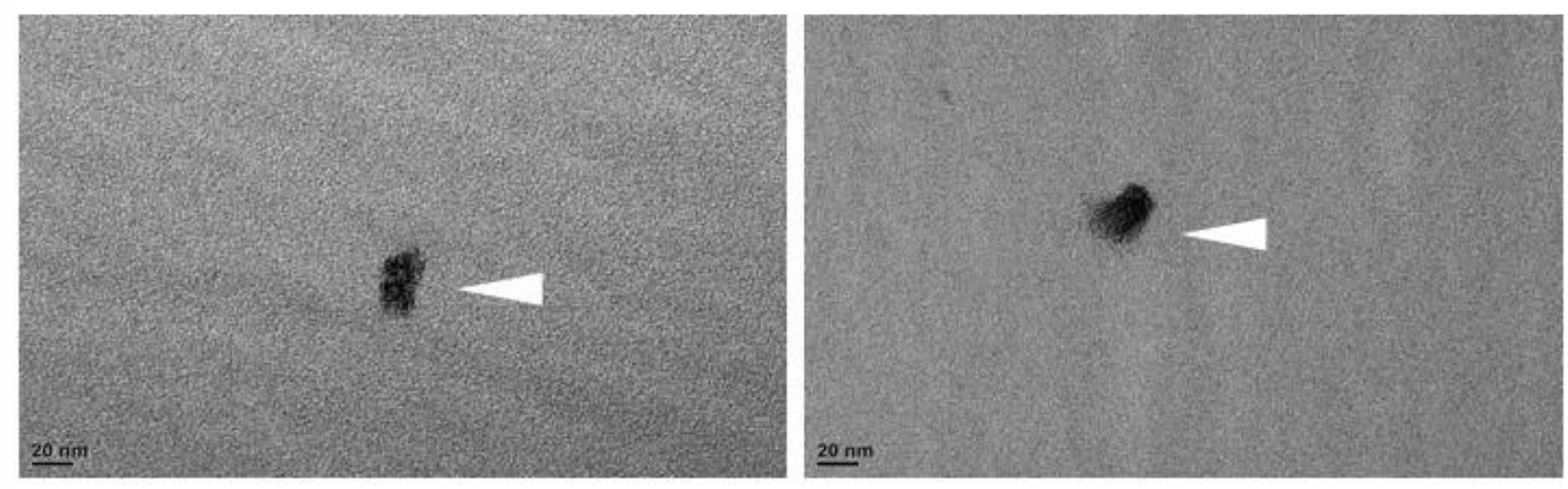

Figure 3. 

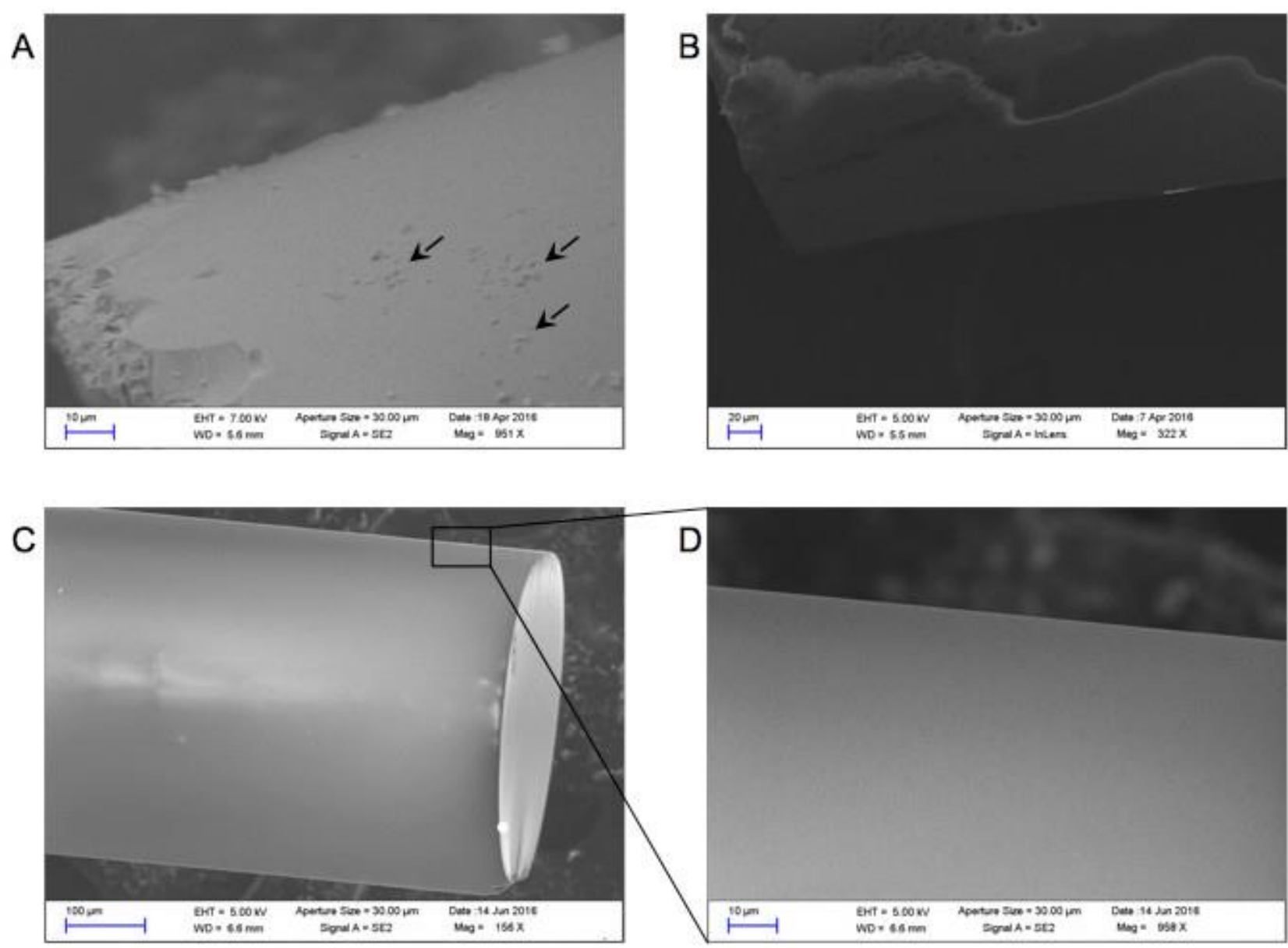

Figure 4. 


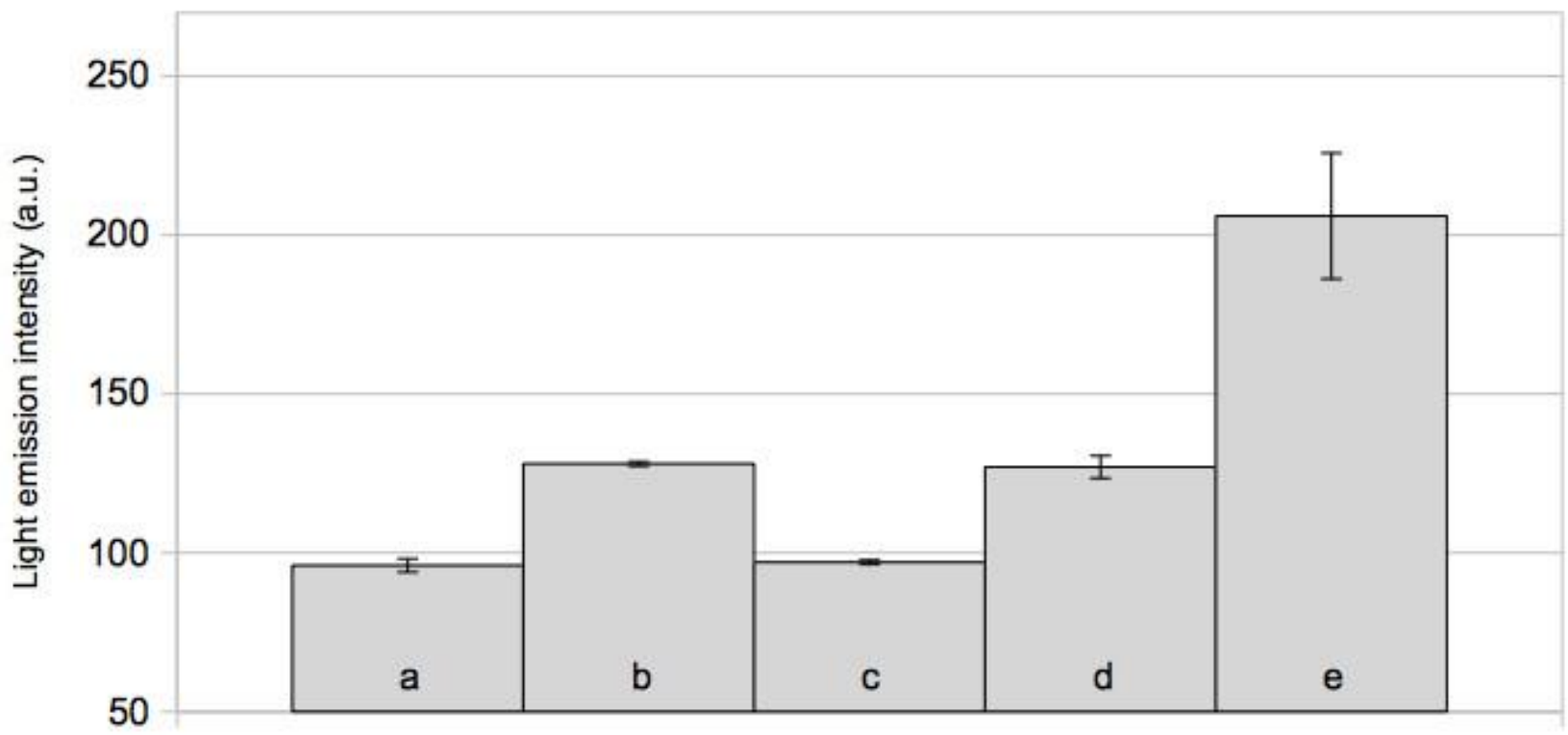

Samples 


\section{Supplementary Information}

\section{DNA origami nanorobot fiber optic genosensor to TMV}

Emanuela Torellia, b, $1^{\star}$, Marisa Manzano ${ }^{\mathrm{a}, \mathrm{b}}$, Sachin K. Srivastava ${ }^{\mathrm{a}}$ \& Robert S. Marks $\mathrm{a}^{\mathrm{a} \mathrm{c}^{*}}$

aNanyang Technological University-Hebrew University of Jerusalem-Ben Gurion University (NEW-CREATE)

Programme, 1 CREATE Way, Research Wing, \#02-06/08, Singapore 138602, Singapore

bDipartimento di Scienze Agroalimentari, Ambientali e Animali

University of Udine, via delle Scienze 206, 33100 Udine, Italy

'Ben-Gurion University of the Negev, Department of Biotechnology Engineering, P.O. Box 653, 84-105, Beer-

Sheva, Israel

${ }^{1}$ Present address: Interdisciplinary Computing and Complex BioSystems (ICOS), School of Computing

Science; Centre for Synthetic Biology and Bioeconomy (CSBB); Centre for Bacterial Cell Biology (CBCB).

Newcastle University, Newcastle upon Tyne, NE1 7RU, U.K.

*Corresponding authors.

E-mail addresses: rsmarks@bgu.ac.il (R.S. Marks); emanuela.torelli@newcastle.ac.uk (E. Torelli). 
Table S1. 3D DNA origami staple sequences labeled with Alexa 488 at the 5' end. Oligonucleotide 3[17] was elongated with a sequence complementary to the capture probe 5'-ACACCACCACCACCACCACA-3'.

\begin{tabular}{|c|c|c|}
\hline Oligo name & Sequence (5'-3') & Length \\
\hline $0[55]$ & Alexa 488-GCCCGGAACCGCCACCCTCAGAGCATAGGAAC & 32 \\
\hline $0[119]$ & Alexa 488-GATTAGCGAGTTAATGCCCCCTGCATGGCTTT & 32 \\
\hline $4[158]$ & Alexa 488-CCCTCAGAACCGCCACCCTCAGAGCCGCCATCTGAAT & 37 \\
\hline $11[17]$ & Alexa 488-GAACGAGGGTAGCAAAGAGGCGAAAGAATA & 30 \\
\hline $12[158]$ & Alexa 488-GGACGTTGGGAAGAATCATTATACCAGTCAAACACTA & 37 \\
\hline $15[72]$ & Alexa488-CGCATAGGGTCGAAATCCGCGACCACAAAGTA & 32 \\
\hline Anchor sequence- & TGTGGTGGTGGTGGTGGTGTTTT- & 53 \\
\hline $3[17]$ & TACAACGCCTGTAGCTGCTAAACAACTTTC & \\
\hline
\end{tabular}




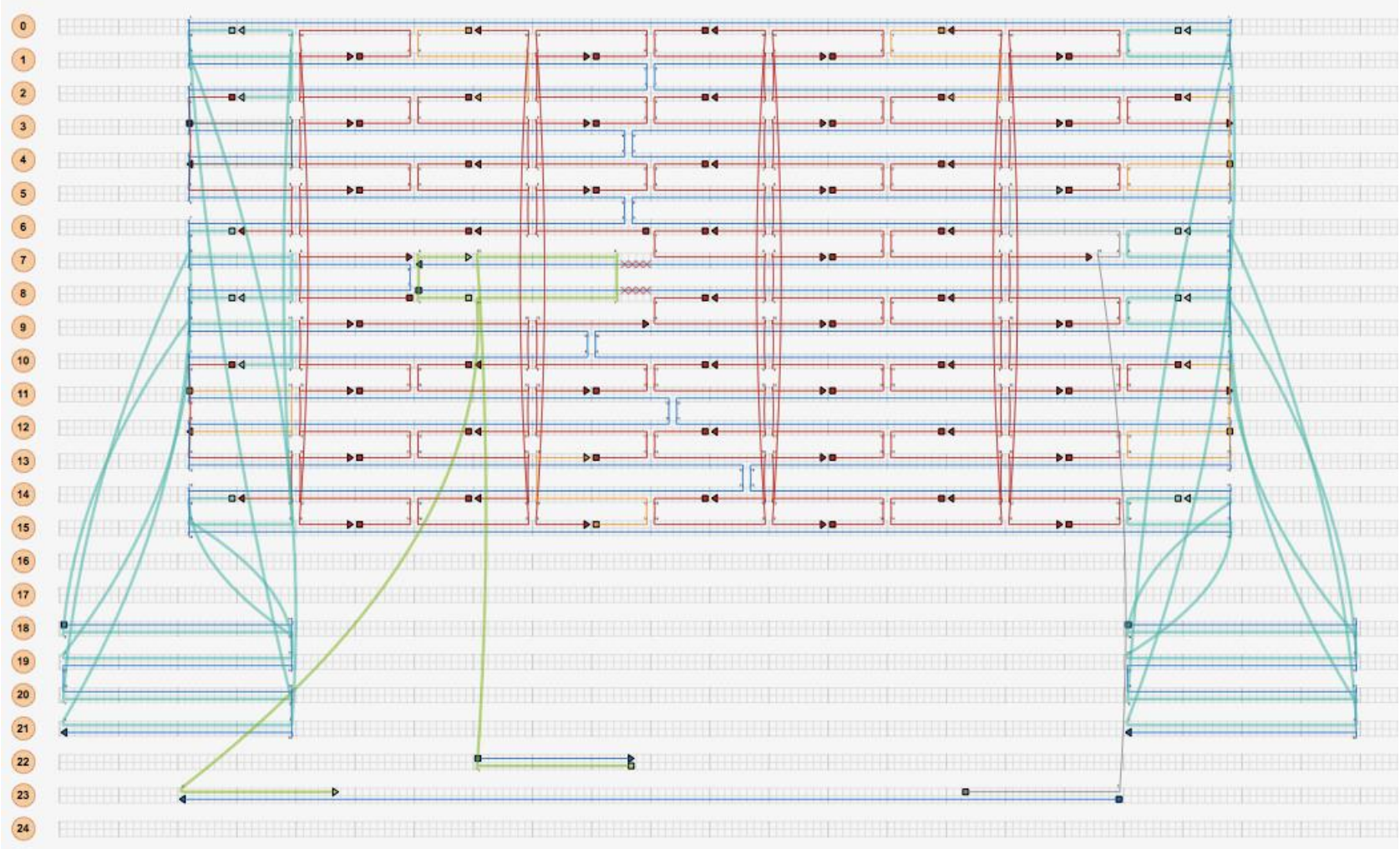

Fig. S1

3D DNA nanorobot design produced in caDNAno software. The scaffold strand (in black) is folded with the staple strands. Oligonucleotides 0[55], 0[119], 4[158], 11[17], 12[158], 15[72] (Torelli et al., 2014) were labeled with Alexa 488 fluorophore (in orange) and oligonucleotide 3[17] was elongated with an anchor sequence (in black). 

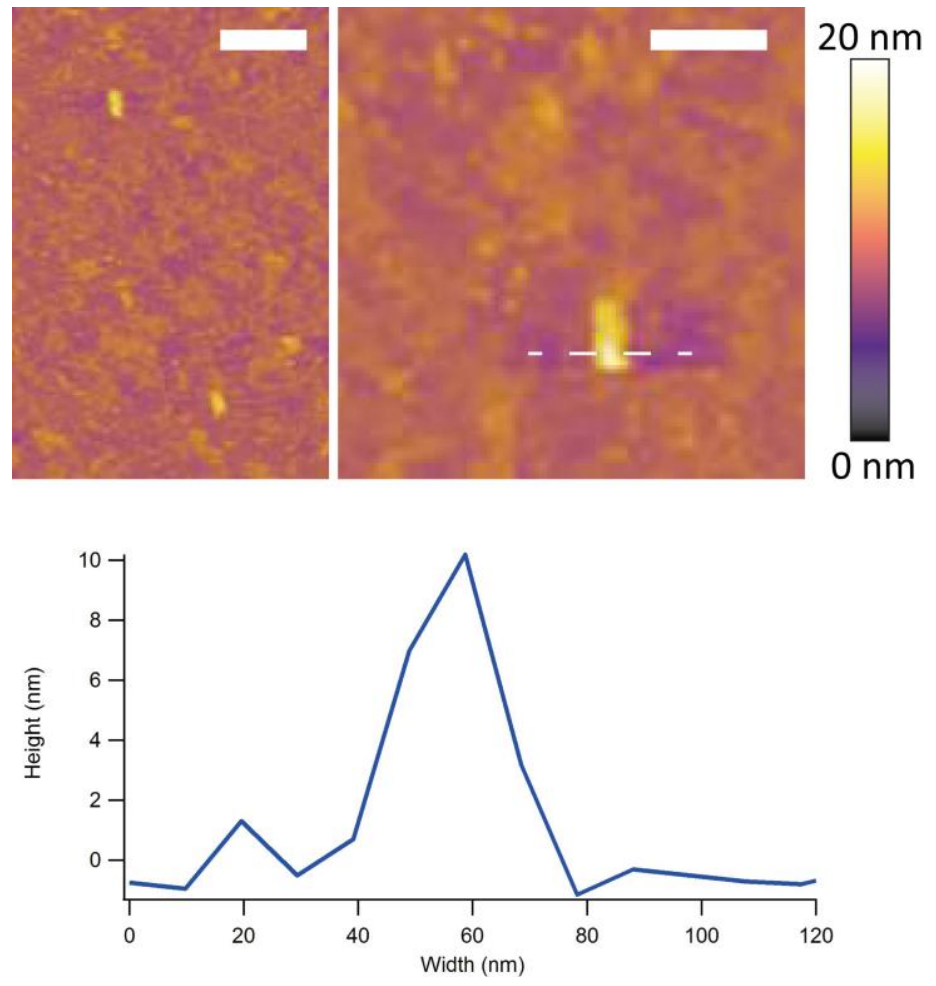

Fig. S2

AFM image of the 3D DNA nanorobot structure (left: scale bar $200 \mathrm{~nm}$, right: scale bar $100 \mathrm{~nm}$ ) and height profile analysis (a white line in the right image). 


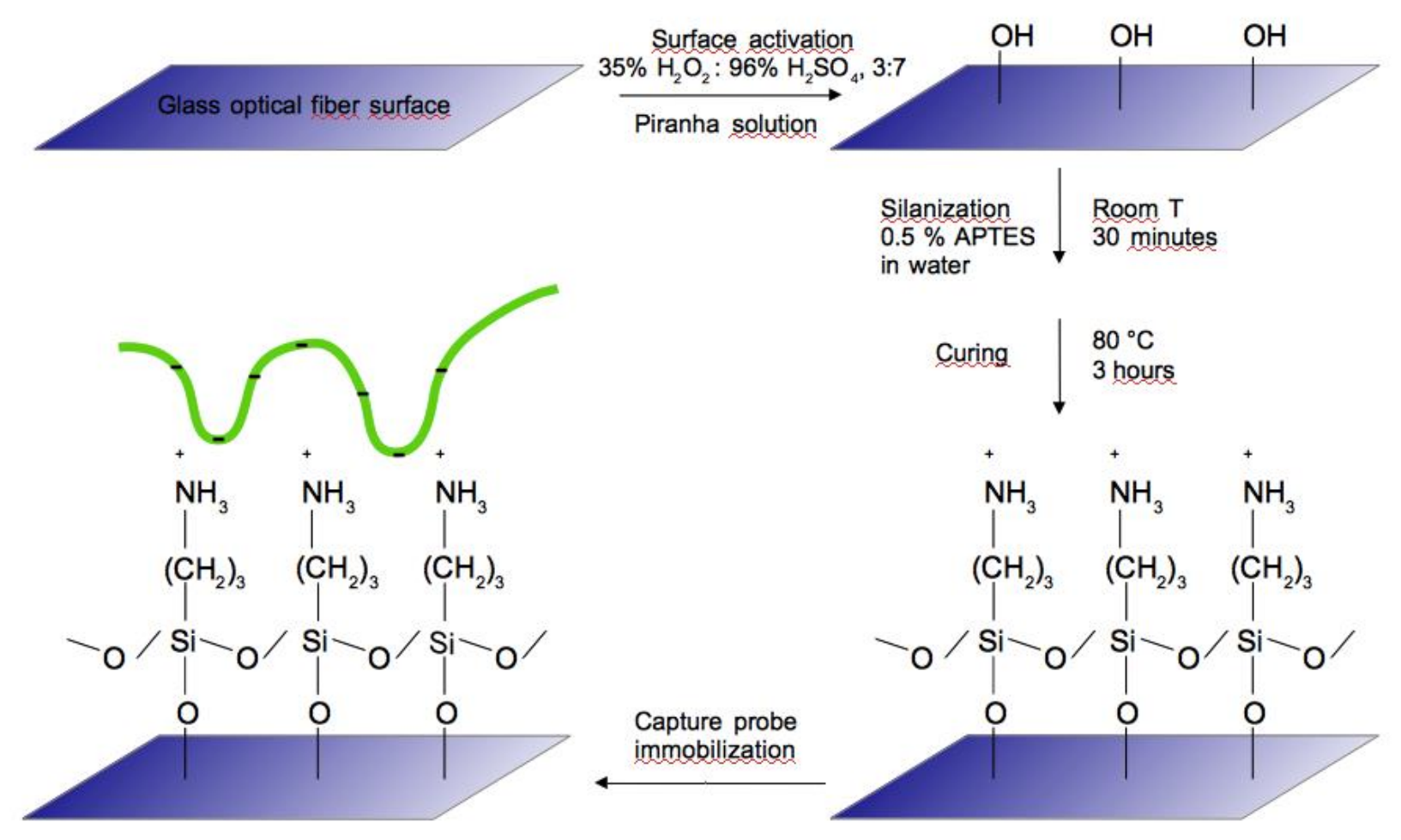

Fig. S3

Schematic illustration representing the capture probe attachment to an amino-silanized glass. The optical glass fiber surface was treated with Piranha solution to introduce hydroxyl groups. Then, during the incubation in $0.5 \%(\mathrm{v} / \mathrm{v})$ APTES in water, the ethoxy groups were hydrolized and condensed into siloxane (Si-O-Si), leading to the formation of a silane monolayer (Metwalli et al., 2006; Vandenberg et al., 1991; Vashist et al., 2014). After silanization, the APTES film curing at $80^{\circ} \mathrm{C}$ for 3 hours increased the siloxane bonds. Finally, the DNA capture probe (in green) was added and the negatively charged backbone bound to the positively charged APTES-coated glass: thus the capture probes were "trapped" upon the surface and were free to form a double helix (Belosludtsev et al., 2001) with complementary anchor DNA sequence protruding from DNA origami nanorobot. 

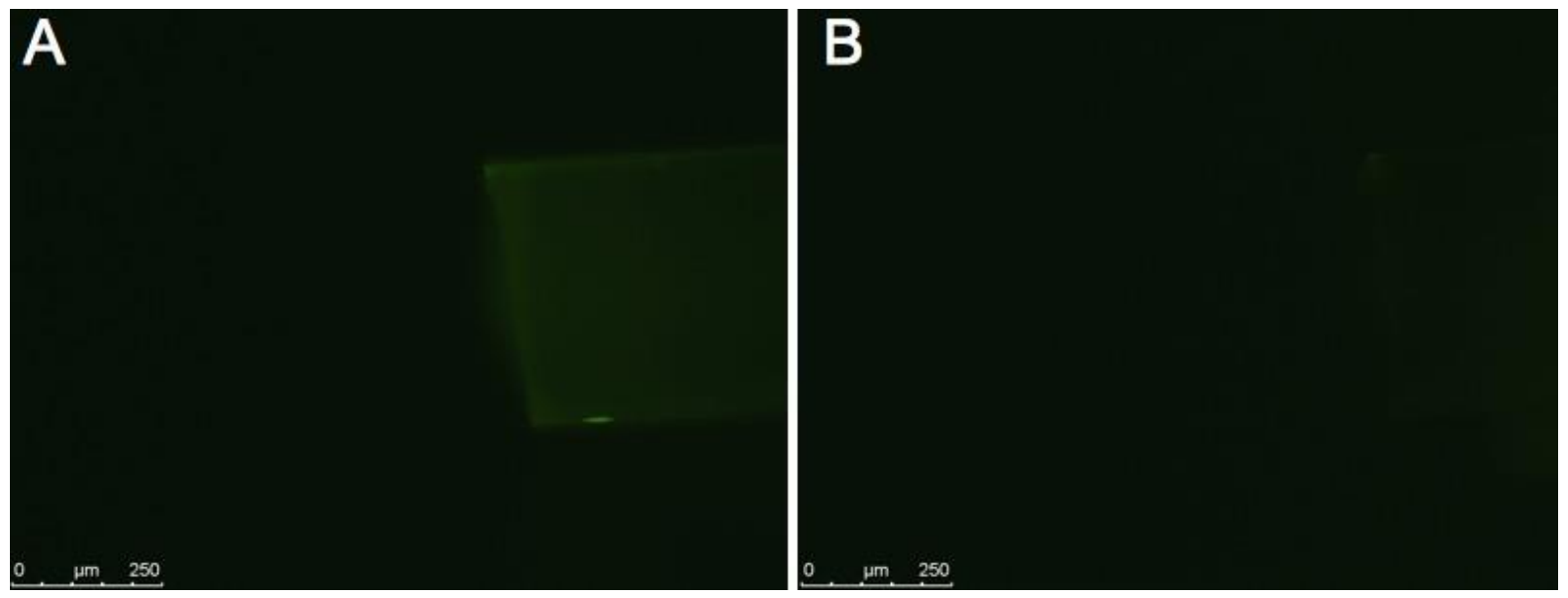

\section{Fig. S4}

Fluorescence images of the optical fiber tips silanized and functionalized with Alexa 488 labeled DNA nanorobots $(A)$ and of the bare fiber $(B)$.

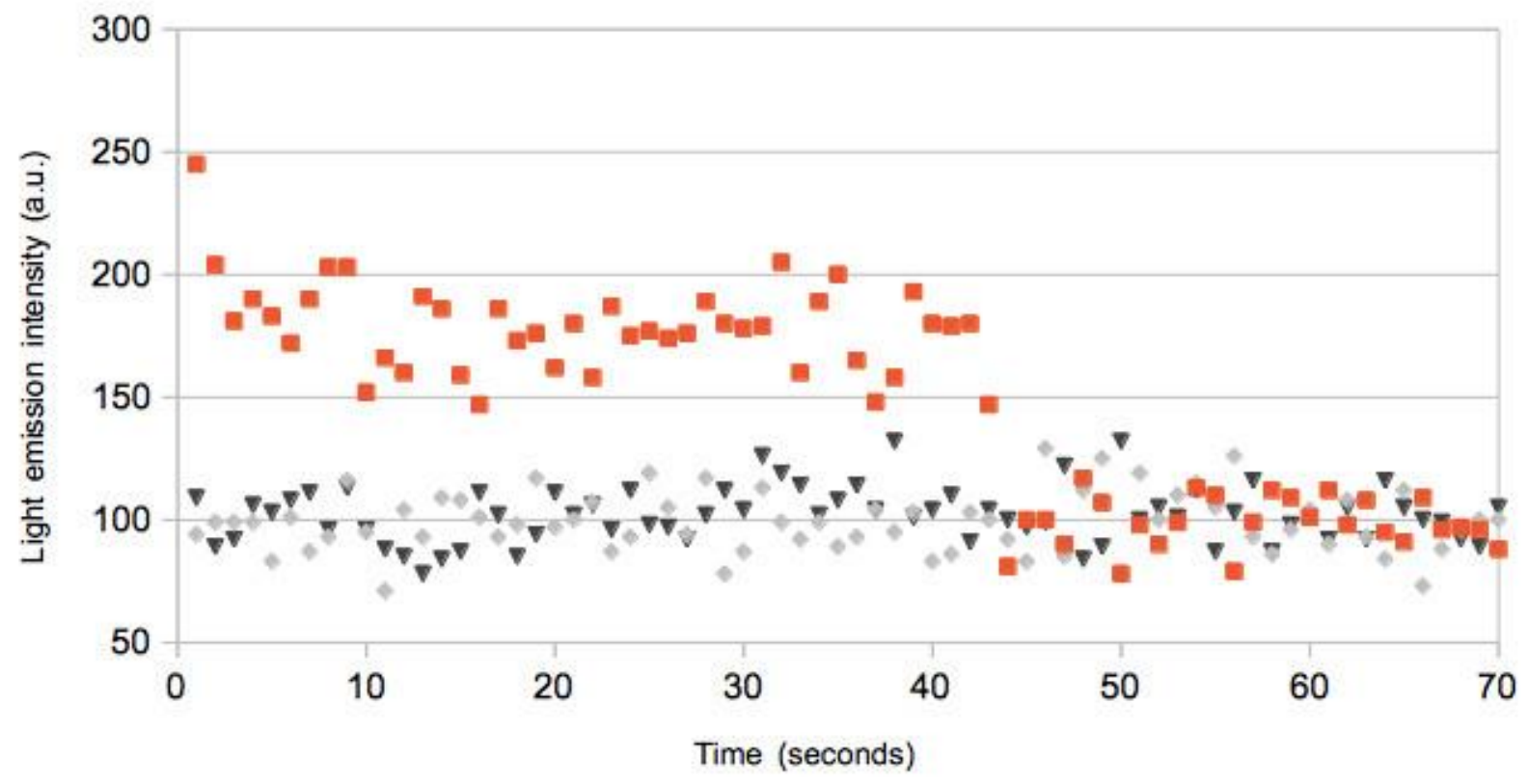

Fig. S5

Light emission intensity (expressed in arbitrary units, a.u.) versus time (expressed in seconds): background 
(in black), hemin/G-quadruplex DNAzyme complex in the absence of the target sequence (closed DNA nanorobot, in grey), hemin/G-quadruplex DNAzyme complex in the presence of the target sequence at a final 